\title{
Gastrointestinal Nematodiasis with Main Emphasis on H.contortus Infection in Small Ruminants
}

\author{
Dipali Parmar*, Shobha, Bhawana Khuswaha and Pooja Sharma
}

ICAR-Indian Veterinary Research Institute, Izatnagar, Uttar Pradesh, India

*Corresponding author

\begin{tabular}{|l|}
\hline K e y w o r d s \\
Nematodiasis, \\
$\begin{array}{l}\text { H.contortus, } \\
\text { Small ruminants }\end{array}$ \\
\hline Article Info \\
\hline $\begin{array}{l}\text { Accepted: } \\
\text { 04 March } 2019 \\
\text { Available Online: } \\
10 \text { April } 2019\end{array}$ \\
\hline
\end{tabular}

\section{Keywords}

Nematodiasis

H.contortus,

Small ruminants

Article Info

Accepted: Available Online

April 2019

\section{A B S T R A C T}

Small ruminant farming serves as a major source of livelihood in rural areas where about $70 \%$ of the population is dependent on agricultural and livestock related activity. In spite of so high potential of these animals, production is significantly constrained due to disease caused by variety of pathogens that include bacteria, virus, protozoa and helminths. Among all these pathogens, parasites are the major cause of sub clinical cases which are not readily diagnosed in field conditions hence affecting production and economic status. These internal parasites cause prolonged and long term effects on animal health and wellness. A reduction in growth rate by $1 / 3$ rd is reported due to helminthic infestation in ruminants. Gastrointestinal nematodes that infect small ruminants mainly fall under Family Trichostrongylidae that consists of many pathogenic nematodes; most important among these is Haemonchus contortus. Pathogenesis of H. contortus is mainly correlated to its haematophagus nature leading to anaemia and high prolificacy causing rapid build-up of infection in the environment. Following review provides a general insight into gastrointestinal nematode parasitism and helps in better understanding of pathogenesis of haemonchosis.

\section{Introduction}

India is primarily an agricultural country with about $70 \%$ of total income from farm and livestock related activities. Sheep and goat farming is a major source of livelihood for small, marginal scale farmers and landless labourers. These animals have been reared since decades for milk, meat, hair and skin around the globe. According to the Food and Agriculture Organisation (FAO, 2013) overall sheep population for the year 2012 was 1.2 billion worldwide, dominated by Asia (44.9\%), followed by Africa (27.6\%) and
America (7.3\%). Sheep and goat population as recorded in 19th livestock census was 65.07 million and 135.17 million, respectively. Internal parasites represent an important cause of disease and loss in production for Sheep and Goat farming. A considerable loss to animal husbandry is caused due to the infection/diseases caused by these parasitic nematodes.

\section{General epidemiology and pathogenesis}

Gastrointestinal parasitism (GIP) is usually caused due to mixed infections with several 
species of the nematodes. Gastro intestinal helminthic infestation is widespread occurring more commonly in tropical and sub-tropical areas. In the past few years the incidence has increased and in India infection reported from ruminants ranged in between $25-78 \%$ (Bandyopandhyay et al., 2010).

GIP incidence is more common in animals reared in open pastures and low cases are obtained from stall fed animals. Infectious stages of the parasites are present in nature and can be transmitted to host animal through ingestion of contaminated pastures and water sources. Infections with these GIT nematodes rarely cause mortality however indirect production and productivity losses are more pronounced.

Infection is more severe and is the cause of fatal disease outcome in animals reared in semi-intensive and free range farming systems. Parasitic nematodes (roundworms) have varied health and economic effects on the productivity and well-being of livestock worldwide. The incidence of helminthic infection varies with the age, sex, season, nutritional status, managemental practices and prevailing agro climatic conditions.

\section{Economic effects}

Harmful effects caused by these parasites are in terms of direct and indirect losses. Pathology caused by these gastrointestinal (GI) parasites is varied (Souls by, 1982) and disease occurrence is mainly dependent on many factors that include interactions between environment, host and parasite Ill effects due to these parasites are mainly in terms of reduced growth rates, decreased milk, meat, fibre quality and additional cost incurred for the treatment of these infections. India being a tropical country faces a major turn over due to these helminthic infections. Monsoon rains combined with availability of suitable climatic conditions sustain propagation and multiplication of these parasitic worms.

Parasitism has indirect effects on animal health by diversion of energy required for normal physiological metabolism to synthesis of various cytokines and immune mediators required for clearing up the established infection. Other symptoms include reduced feed intake due to anorexia and increased susceptibility to other pathogens (Sykes and Coop, 2001; Moreau et al., 2010). Changes in body composition of affected animals occur, thereby making animals more susceptible to other concurrent infections (DominguezTorano et al., 2000).

Most of the nematodes that infect gastrointestinal tract of ruminants belong to the family Trichostrongylidae. Among these Haemonchus contortus, Trichostrongylus colubriformis are highly evolved and are major production limiting factor in sheep. Other species involved are Cooperia, Nematodirus, Oesophagostomum, Chabertia ovina, Bunostomum trigonocephalum, Skrjabinema ovis and Trichuris spp. Disease caused by these parasites is varied in nature with clinical signs ranging from diarrhoea, constipation, weakness, decreased growth/production rates and reduced wool/fibre quality. Combined effect of these parasites leads to growth retardation with prolonged debility condition in affected animals. As no farm animal is free from these gut parasites and get infected by these once in their lifetime, hence making deworming an essential component of farm management programme.

\section{Haemonchosis}

Among all gastrointestinal parasites most pathogenic and widely prevalent gut nematode in sheep and goat is 
Haemonchuscontortus, the blood feeding abomasal parasite. Haemonchosis caused by $H$. contortus represents $\sim 15 \%$ of all gastrointestinal diseases of small ruminants world-wide and results in extensive financial losses.

In India three species have been reported viz., $H$. contortus (Sheep, goat, cattle and other ruminants), $H$. similis (cattle, deer) and H.longistipes (camel). Estimated losses due to the treatment in India alone for Haemonchus contortus is $\$ 103$ million (Waller and Chandrawathani, 2005). Haemonchus is among the most fecund strongylid nematodes with a pre patent period of 18-21 days. Adult female lays about five thousand eggs per day that are passed out in the faeces of affected animal leading to pasture contamination. No association between age and animal class exist regarding disease occurrence however haemonchosis is more common in lactating ewes and young lambs due to relaxtion of immunity and absence of maternal antibodies to stop upcoming infection (Taylor et al., 2007).

Clinical haemonchosis is mainly classified into three types depending upon intensity of worm burden that is hyper acute, acute and chronic form (Souls by, 1982; Taylor et al., 2007). Hyper acute haemonchosis occurs due to sudden massive uptake of large doses of infective $L_{3}$ larvae. It is less common in nature and leads to haemorrhagic anaemia causing dark coloured faeces and sudden death due to acute blood loss. This form is most common in lambs and lactating ewes due to break in the immunity. Animal is usually found dead without any preliminary signs. The possible pathogenic mechanism, which is responsible for cause of death in haemonchosis is hemorrhagic anaemia, hypoproteinemia and oedema due to vital blood sucking by both $\mathrm{L}_{4}$ and adults. Moreover, diarrhoea causes fluid loss and dehydration resulting in hypovolaemic shock. Infected animals become progressively weak and are reluctant to move with the development of bottle jaw condition as a result of submandibular oedema.

Le Jambre (1995) reported that a close positive correlation exists between number of parasity and severity of infection. In chronic cases, symptoms similar to malnutrition as depicted by poor weight gain, break in wool are prominent due to excessive blood loss. However, compensatory mechanism occur but in the absence of proper treatment bone marrow continuously gets exhausted as a result of loss of iron and proteins in tract leading to death. Daily loss in weight upto $30 \mathrm{~g} /$ day has been reported in sheep and goat infected with small but prolonged cases (Beriajaya and copeman, 2006).

On post mortem examination pin point haemorrhages can be seen on abomasa mucosa which is oedematous. There is presence of thin barber pole like worms with are about $2 \mathrm{~cm}$ in length on entire mucosa. Presence of frank blood is evident on mucosal surface with pale mucus membranes and ascites condition.

Main economic losses are due to reduced weight gain and prolonged emaciation because of impaired digestion and decreased absorption of protein, calcium and phosphorus (Sood, 1981). About 30-40\% mortality has been reported in lambs due to haemonchosis if no timely treatment with proper anthelmintic is undertaken (Kalita et al., 1978).

The presence of $H$. contortus in the abomasum appears to interfere with the digestion and absorption of proteins, calcium and phosphorus (Sood, 1981). Increased susceptibility to Haemonchus infection in goats has been reported in animals with 
vitamin A and calcium defeciencies (Kumar and Deo, 1970).

Disturbance in the levels of various haematological and biochemical parameters have been observed in clinical haemonchosis. Drop in hemoglobin, haematocrit (PCV), TEC, RBC level, serum protein and albumin is more pronounced in affected animals (Ijaz et al., 2009).Infection with $H$. Contortus produces serious effect on serum biochemistry and enzymatic assays particularly the change in the levels of acidic phosphate, alkaline phosphate (ALP), aspartate aminotransferase (AST) or serum glutamate oxalate transaminase (SGOT) and alanine aminotransferase (ALT) or serum glutamate pyruvate transaminase (SGPT) (Hassan et al., 2013).

Various laboratory tests have been employed for the diagnosis of the condition. Most common among these is faecal flotation followed by egg counting by modified McMaster technique to know severity of the infection. Faecal culture to differentiate various nematode larvae is widely accepted. In this larvae are morphologicaly differentiated and identified as per the standard keys provided by various workers (Yamaguti, 1960; Soulsby, 1982 Van Wyk and Mayhew, 2013)

Due to high pathogenicity and wide prevalence of haemonchosis, various control measures have been adopted, which involve both chemical and non-chemical control measures. Despite availability of combination of various anthelmintics along with pasture and grazing management, H.contortus remains major threat to sheep and goat industry. This is due to development of resistance to many of the commercially available anthelmintics. Current control strategies against $H$. contortus are mainly by use of anthelmintic drugs. However, widespread use of anthelmintics has led to serious drug resistance problems in domestic animals worldwide (Kaplan and Vidyashankar, 2012). A new class of anthelmintic, the aminoacetonitrile derivatives introduced recently like monepantel, have also reported to acquired resistance (Scott et al., 2013).

Hence, due to widespread anthelmintic resistance and demand for clean, green, residue free animal products, there is need for alternative approach to combat haemonchosis. Under IPM (Integrated pest management) combination of various anthelmintics along with other nonchemical methods are used. This includes grazing management, nutritional management, genetic selection or breeding methods (Kelly et al., 2013), biological control by use of medicinal plants (Iqbal et al., 2007), use of nematophagus fungi (Waller and Larsen, 1993; Larsen, 2000) and strategic treatment of the affected animals by anaemia assessment using FAMACHA (van Wyk and Bath, 2002; Kaplan et al., 2004).

Selective treatment of individual animals instead of treating all animals is another economic strategy for control of $H$. contortus. The FAMACHA system, which involves comparison of conjunctival mucous membrane color with an eye color chart to determine the severity of anemia, is used to decide whether an animal needs treatment (Kaplan et al., 2004). This method has facilitated quick identification of $H$. contortus infected sheep and goats without the aid of any laboratory procedures and delivers the treatment only to those who require it (Vatta et al., 2009; Kaplan et al., 2004). Other strategies adopted to reduce risk of haemochosis include adequate nutrition to pregnant ewes and lambs including good quality protein and trace mineral/vitamins so as to naturally boost up immune mechanism 
(Macarthur et al., 2014). Superior nutrition also increases resilience in animals against infection.

In conclusion, gastrointestinal nematodiasis is ubiquitous with haemonchosis at the top of the list. These parasites lead to prolonged debility and emaciation in affected animals. Almost every farm animal gets infected with GIP once in their entire life period. Economic losses by these nematodes occur in varied form directly and indirectly affecting animal production status. Because of high pathogenicity various control measures have been adopted to combat the problem due to parasitism. These include various chemicals and non-chemical methods along with integrated pest management (IPM) programme which are of utmost importance. Nematode species are evolving and have developed resistance to various anthelmintics mainly of genera Haemonchus, Ostertagia, and Trichostrongylus therefore making them economically important.

\section{References}

Bandyopadhyay S, Mandal S, Datta KK, Devi P, De S,Bera AKand Bhattacharya D. 2010. Economic analysis of risk of gastrointestinal parasitic infection in cattle in North Eastern States of India. Tropical Animal Health and Production. 42: 1481-1486.

Beriajaya and Copeman DB. 2006. Haemonchus contortus and Trichostrongylus columbriformis in pen-trials with Javanese thin tail sheep and Kacang cross Etawah goats. Veterinary parasitology. 315-323.

Dominguez-Torano I A, Cuquerella M, GomezMunoz M T, Mendez S, FernandezPerez F J and Alunda J M. 2000. Vaccination of Manchego lambs against Haemochus contortus with a somatic fraction (p26/23) of adult parasites. Parasite Immunology. 22(3):131-138.
FAO S. 2013. FAOSTAT database. Food and Agriculture Organization of the United Nations, Rome, Italy

Hassan MM, Hoque MA, Islam SKMA, Khan SA, Hossain MB and Bhanu Q. 2013. Efficacy of anthelmintics against parasitic infections and their treatment effect on the production and blood indices in Black Bengal goats in Bangladesh. Turkish Journal of Veterinary and Animal Science. 36(4): 400-408.

Ijaz M, Khan MS, Avais M, Ashraf K, Ali MM and Khan MZU. 2009. Infection rate and chemotherapy of various helminths in diarrhoeic sheep in and around Lahore. Journal of Animal and Plant Science. 19: 13-16.

Iqbal Z, Sarwar M, Jabbar A, Ahmed S, Nisa M, Sajid MS, Khan MN, Mufti KA and Yaseen M. 2007. Direct and indirect anthelmintic effects of condensed tannins in sheep. Veterinary Parasitology. 144: 125-131.

Kalita C L, Gautam O P and Banerjee D P. 1978. Fenbendazole against Haemonchosis in sheep. Indian Veterinary Journal. 55: 660-662.

Kaplan R M and Vidyashankar A N. 2012. An inconvenient truth: global worming and anthelmintic resistance. Veterinary Parasitology. 186: 70-78.

Kaplan RM, Burke JM, Terrill TH, Miller JE, Getz WR, Mobini S, Valencia E, Williams MJ, Williamson LH, Larsen $M$ and Vatta AF. 2004. Validation of the FAMACHAC eye color chart for detecting clinical anemia in sheep and goats on farms in the southern United States. Veterinary Parasitology. 123: 105-120.

Kelly GA, Kahn LP and Walkden-Brown SW. 2013. Measurement of phenotypic resilience to gastro-intestinal nematodes in Merino sheep and association with resistance and production variables. Veterinary Parasitology. 193: 111-117.

Kumar V and Deo P G. 1970. The effects of Vitamin A, Protein, Calcium and 
Phosphorus deficient diet upon the natural resistance of goats to Haemonchus spp. Ceylon Veterinary journal. 18: 119-122.

Larsen M. 2000. Prospects for controlling animal parasitic nematodes by predacious micro fungi. Parasitology. 120: 121-131

Le Jambre LF. 1995. Relationship of blood loss to worm numbers, biomass and egg production in Haemonchus contortus infected sheep. International Journal of Parasitology. 25, 269-273.

Macarthur FA, Khan L, Windon RG. 2014. The influence of dietery manipulations and gastrointestinal nematodes on twinbearing merino ewes and determinants of lamb survival. Livestock Science. 157: 342-352.

Moreau E, Chauvin A, Moreau E, Chauvin A. 2010. Immunity against Helminths: Interactions with the Host and the Intercurrent Infections. BioMedical Research International.

Scott I, Pomroy WE, Kenyon PR, Smith G, Adlington B and Moss A. 2013. Lack of efficacy of monepantel against Teladorsagia circumcincta and Trichostrongylus colubriformis. Veterinary parasitology. 198: 166-171.

Sood M L. 1981. Haemonchus in India. Parasitology. 83: 639-650.

Soulsby E J L. 1982. Helminths, arthropods and protozoa of domesticated animals (No. Ed. 7). Bailliere Tindall.

Sykes AR, Coop RL. 2001. Interaction between nutrition and gastrointestinal parasitism in sheep. New Zealand Veterinary
Journal. 49:222-226.

Taylor MA, Coop RL and Wall RL. 2007. Veterinary Parasitology. Third ed Blackwell Publishing. 159-161

van Wyk JA and Bath GF. 2002. The FAMACHA system for managing haemonchosis in sheep and goats by clinically identifying individual animals for treatment. Veterinary Research. 33: 509-529.

Van Wyk JA and Mayhew E. 2013. Morphological identification of parasitic nematodes infective larvae of small ruminants and cattle: a practical lab guide. Journal of Veterinary Research. 80: 1-14.

Vatta AF, Waller PJ, Githiori JB and Medley GF. 2009. The potential to control Haemonchus contortus in indigenous South African goats with copper oxide wire particles. Veterinary Parasitology. 162: 306-313

Waller P J and Chandrawathani P. 2005. Haemonchus contortus: parasite problem No. 1 from Tropics-Polar circle. Problems and prospects for control based on epidemiology. TropicalBiomedicine. 22: 131-137.

Waller PJ and Larsen M. 1993. The role of nematophagous fungi in the biological control of nematode parasites of livestock. International journal of parasitology. 23: 539-546.

Yamaguti S. 1961. Systema Helminthum. The nematodes of vertebrates. Volume III. Interscience Publishers Ltd., London.

\section{How to cite this article:}

Dipali Parmar, Shobha, BhawanaKhuswaha and Pooja Sharma. 2019. Gastrointestinal Nematodiasis with Main Emphasis on $H$ contortus Infection in Small Ruminants. Int.J.Curr.Microbiol.App.Sci. 8(04): 284-289. doi: https://doi.org/10.20546/ijcmas.2019.804.032 